\title{
DEVELOPMENT OF NEW TAXONOMY OF INAPPROPRIATE COMMUNICATION AND ITS APPLICATION TO OPERATING TEAMS IN NUCLEAR POWER PLANTS
}

\author{
AR RYUM KIM ${ }^{1}$, JINKYUN PARK ${ }^{2}$, SEUNG WOO LEE ${ }^{1}$, INSEOK JANG ${ }^{1}$, HYUN GOOK KANG ${ }^{1,3}$, \\ and POONG HYUN SEONG ${ }^{1 *}$ \\ ${ }^{1}$ Department of Nuclear and Quantum Engineering, Korea Advanced Institute of Science and Technology \\ 373-1, Guseong-dong, Yuseong-gu, Daejeon 305-701, Republic of Korea \\ ${ }^{2}$ Integrated Safety Assessment Division, Korea Atomic Energy Research Institute \\ 150-1, Dukjin-dong, Yuseong-gu, Daejeon 305-353, Republic of Korea \\ ${ }^{3}$ Department of Nuclear Engineering, Khalifa University of Science, Technology and Research \\ P.O.Box 127788, Abu Dhabi, UAE \\ *Corresponding author. E-mail : phseong@kaist.ac.kr
}

Received November 25, 2011

Accepted for Publication February 08, 2012

Inappropriate communications can cause a lack of necessary information exchange between operators and lead to serious consequences in large process systems such as nuclear power plants (NPPs). In this regard, various kinds of taxonomies of inappropriate communications have been developed to prevent inappropriate communications. However, there seems to be difficult to identify inappropriate communications from verbal protocol data between operators. Because the existing taxonomies were developed for use in report analysis, there is a problem of 'uncertainty'. In consequence, this paper proposes a new taxonomy of inappropriate communications and provides some insights to prevent inappropriate communications. In order to develop the taxonomy, existing taxonomies for four industries from 1980 to 2010 were collected and a new taxonomy is developed based on the simplified one-way communication model. In addition, the ratio of inappropriate communications from 8 samples of audio-visual format verbal protocol data recorded during emergency training sessions by operating teams is compared with performance scores calculated based on the task analysis. As a result, inappropriate communications can be easily identified from the verbal protocol data using the suggested taxonomy, and teams with a higher ratio of inappropriate communications tend to have a lower performance score.

KEYWORDS : Inappropriate Communications, Verbal Protocol Data, Operating Team, Taxonomy of Inappropriate Communications

\section{INTRODUCTION}

Large process control systems such as nuclear power plants (NPPs), railway systems, and aviation systems are operated by teams consisting of several operators. An important aspect of a team is an interaction and coordination of operators within workplaces. In this environment, communication is necessary to share information between individuals, coordinate actions on the system, pool expert resources to solve problems, and as a mean of validating system knowledge [1].

However, inappropriate communications can cause a lack of necessary information to operate the systems and lead to serious consequences in the systems. For example, in 1997, Korea Air Flight 801 from Seoul to Guam crashed into hilly terrain because of inappropriate communications. The major causes for this accident were the captain's fail- ure to adequately brief and the first officer's and flight engineer's failure to cross check the captain's execution of the approach [2]. Because of this accident, the airplane impacted at Nimitz hill, Guam, $4.8 \mathrm{~km}$ from the airport, and 228 of 254 passengers and crews were killed.

Moreover, Y. Hirotsu reported that $25 \%$ percent of human error in NPPs is connected to written or verbal communication related to the operation of NPPs [3]. In addition, $P$. Murphy pointed out that $92 \%$ of incidents in railway systems involves inappropriate communications during railway maintenance [4]. Similarly, R. L. Grayson and C. E. Billings stated that $70 \%$ of reports from the aviation safety reporting system (ASRS) involve inappropriate communications related to the operation of an aircraft [5].

Accordingly, many researchers have endeavored to reduce inappropriate communications in order to secure 
the safety of large process control systems. According to Morrison and Wright [6], there is a corresponding trend toward an increasing number of inappropriate communications under high workload and time pressure situations in large process control systems. S. H. Kim et al. [7] and J. K. Park [8] investigated the communication characteristics of operating teams under off-normal conditions of NPPs to provide useful insights for preventing inappropriate communications.

Moreover, various types of taxonomies of inappropriate communications have been developed to investigate the causes and consequences of inappropriate communications. J. Berman and H. Gibson developed a taxonomy of inappropriate communications to identify the nature and scope of inappropriate communications in NPPs, and to identify practical defenses [1]. Similarly, H. Gibson et al. proposed inappropriate communication taxonomy to enable detailed investigation of inappropriate railway track maintenance communications [9]. In addition, Morrow et al. developed a taxonomy to identify, understand, and explain why inappropriate communications occur during routine operation of commercial aircraft [10].

However, taxonomies from previous researches seem to have difficulty identifying inappropriate communications from the verbal protocol data since most of them were developed for use on reports which were submitted during an accident. For example, it is ambiguous to define a taxonomical element such as 'misunderstanding' because it is difficult to identify whether the receiver understands the message of the speaker in verbal protocol data [11]. In order to unravel this problem, it is necessary to develop a new taxonomy of inappropriate communications that is available to be used as a criterion to identify inappropriate communications without any uncertainty regarding the verbal protocol data.

In this regard, the purpose of this paper is to propose a new taxonomy of inappropriate communications, and the ratio of inappropriate communications that is based on the developed taxonomy is compared with the performance score of 8 operating teams under emergency training sessions of NPPs. To this end, various categories of inappropriate communications were collected from four domains - the nuclear industry, aviation industry, railway industry, and medical industry - from 1980 to 2011. Using the collected inappropriate communications, a new taxonomy is developed that is based on the simplified one-way communication model. Inappropriate communications from 8 samples of audio-visual format verbal protocol data recorded under emergency training sessions of NPPs are identified based on the taxonomy and the result is compared with a performance score based on the task analysis. Consequently, it is found that inappropriate communications can be identified using the new taxonomy without 'uncertainty', and that the performance score is decreased when team members utter a greater amount of inappropriate communications.

\section{PREVIOUS STUDIES ON THE TAXONOMY OF INAPPROPRIATE COMMUNICATIONS}

Many researchers have exerted a great deal of effort to develop taxonomies to investigate the causes and consequences of inappropriate communications to secure the safety of large process control systems such as those in the nuclear, the aviation, the railway and the medical industries. However, it is difficult to identify inappropriate communications from the verbal protocol data due to the problem of uncertain criteria used in previous studies since existing taxonomies have been developed for use in report analysis. For this reason, in order to develop a new and more practical taxonomy for inappropriate communications, relevant literatures published in the four abovementioned industrial domains from 1980 to 2011 were reviewed. Table 1 shows an overview of literature in the four industries.

From Table 1, it seems that developing taxonomies of inappropriate communications started in the aviation industry and spread to the other industries. In addition, taxonomies of inappropriate communications have only recently begun to be studied in the railway and medical industries.

\subsection{Existing Taxonomies in Nuclear Fields}

J. L. Seminara and R. W. Pack [12] tried to remedy existing problems and to design more effective systems for new nuclear power plants. They classified inappropriate communications between operators in the main control room (MCR) and local operators (LOs) according to communication devices. J. Berman and H. Gibson [1] tried to formulate a clearer understanding of the causes of inappropriate communications, and the means of preventing such failures during the operation of NPPs. They categorized inappropriate communications based on information processing models involving the sender, medium, and receiver of the communications. U. S. NRC [13] defined specific criteria for evaluating the effectiveness of corrective action plans, interview protocols, and an observation protocol related to communication processes. They divided inappropriate communications into sending errors and receiving errors. R. Fukuda and O. Strater [14] investigated safetyrelated events influenced by inappropriate communications and their contributing factors and then conducted detailed investigations into the cognitive aspects of the incidents, which may clarify inappropriate communications. They defined inappropriate communications as misunderstanding, lack of communication, and breakdown of communication. S. M. Lee et al. [15] showed that the human communication process and human actions depend on the conditions under which the action takes places by adopting an approach based on the cognitive reliability and error analysis method (CREAM). They categorized inappropriate communications as timing, acoustic features, channel, contents, and sequence. Table 2 shows the taxonomy of inappropriate communications that has been developed in the nuclear industry. 
Table 1. The Overview of Literatures about Taxonomy of Inappropriate Communications in four Industries

\begin{tabular}{|c|c|c|c|c|}
\hline & Nuclear & Aviation & Railway & Medical \\
\hline 1980-1985 & $\begin{array}{l}\text { Communication needs of the } \\
\text { nuclear power plant operator } \\
\text { (B.J. Seminara et al., 1982) }\end{array}$ & $\begin{array}{c}\text { Information transfer between } \\
\text { air traffic control and aircraft: } \\
\text { communication problems in } \\
\text { flight operation } \\
\text { (R.L. Grayson et al., 1981) }\end{array}$ & & \\
\hline 1986-1990 & & $\begin{array}{l}\text { ATC control and commu- } \\
\text { nication problem: an over- } \\
\text { view of recent ASRS data } \\
\text { (R. Morrison et al., 1989) }\end{array}$ & & \\
\hline 1991-1995 & $\begin{array}{c}\text { Communication failure in the } \\
\text { operation of nuclear power } \\
\text { plants } \\
\text { (J. Berman et al., 1994) }\end{array}$ & $\begin{array}{l}\text { Nonroutine transactions in } \\
\text { controller-pilot } \\
\text { communication } \\
\text { (D. Morrow et al., 1991) }\end{array}$ & & $\begin{array}{l}\text { Safety in the operating } \\
\text { theatre - Part 2: Human error } \\
\text { and organisational failure } \\
\text { (J. Reason, 1995) }\end{array}$ \\
\hline $1996-2000$ & $\begin{array}{c}\text { NUREG-1545 } \\
\text { (U.S. NRC, 1997) }\end{array}$ & $\begin{array}{l}\text { Pilot-controller } \\
\text { communication errors: an } \\
\text { analysis of aviation safety } \\
\text { reporting system (ASRS) } \\
\text { (J.A. Volpe et al., 1998) }\end{array}$ & $\begin{array}{l}\text { Methods for safety analysis } \\
\text { in railway systems } \\
\text { (K. Oien \& R. Rosness, 1998) }\end{array}$ & \\
\hline 2001-2005 & $\begin{array}{c}\text { Communication in nuclear } \\
\text { power plants } \\
\text { (O. Strater et al., 2004) }\end{array}$ & $\begin{array}{l}\text { The effect of workload and } \\
\text { decision support automation } \\
\text { on enroute R-side and D-side } \\
\text { communication exchange } \\
\text { (L.L. Bailey et al., 2001) }\end{array}$ & $\begin{array}{l}\text { The role of communication } \\
\text { in accidents and incidents } \\
\text { during rail possessions } \\
\text { (P. Murphy, 2001) The role } \\
\text { of communication errors in } \\
\text { railway incident causation } \\
\text { (P. Shanahan et al, 2005) }\end{array}$ & $\begin{array}{c}\text { Lecture note } \\
\text { (T. Matsuo, 2005) }\end{array}$ \\
\hline 2006-2011 & $\begin{array}{c}\text { CREAM-based } \\
\text { communication error analysis } \\
\text { method (CEAM) for nuclear } \\
\text { power plants operators' } \\
\text { communication } \\
\text { (S. M. Lee, 2010) }\end{array}$ & $\begin{array}{l}\text { Human error data collection } \\
\text { as a precursor to the } \\
\text { development of human } \\
\text { reliability assessment } \\
\text { capability in air traffic } \\
\text { management } \\
\text { (B. Kirwan et al., 2008) }\end{array}$ & $\begin{array}{c}\text { A taxonomy of human } \\
\text { communication errors and } \\
\text { application to railway track } \\
\text { maintenance } \\
\text { (W. H. Gibson et al., 2006) }\end{array}$ & $\begin{array}{l}\text { Communication failure in the } \\
\text { operating room } \\
\text { (A.L. Halverson et al., 2010) }\end{array}$ \\
\hline
\end{tabular}

\subsection{Existing Taxonomies in Aviation Field}

R. L. Grayson and C. E. Billings [5] discussed inappropriate communications between pilots and controllers. They classified inappropriate communications focusing on how well information is transferred between pilots and controllers. R. Morrison [6] reviewed the narrative reports submitted to the aviation safety reporting system (ASRS) database and investigated variables of interest associated with inappropriate communications, including controller workload, traffic volume, frequency congestion, air traffic control (ATC) communications, and facility management policy. In that study, inappropriate communications were then divided into four types. D. Morrow et al. [16] examined how a collaborative scheme is used to balance the demands of accuracy and efficiency during routine pilot and controller communication. They identified two general kinds of inappropriate communications: understanding problems and information problems. J. A. Volpe [17] identified the factors that contribute to inappropriate communications to reduce the incidence of inappropriate communications. His taxonomy was developed based on a readback/hearback loop. L. L. Bailey et al. [18] examined the effects of aircraft density and automated decision aids on communication exchanges between en route air traffic control teams. The existing taxonomy of inappropriate communications, which is the Federal Aviation Administration (FAA) ATC operational error reporting forms, was used in that study. B. Kirwan et al. [19] collected human error probabilities (HEPs) via analyzing the results of a realtime simulation involving air traffic controllers (ATCOs) and pilots with a focus on inappropriate communications. They identified inappropriate communications based on the transcripts between ATCOs and pilots, and their classification includes some elements which may not strictly be errors, but highlights issues with communication management. Table 3 shows the taxonomy of inappropriate communications that has been developed in the aviation industry. 
Table 2. Existing Taxonomies of Inappropriate Communications in the Nuclear Industry

\begin{tabular}{|c|c|c|}
\hline Authors (Year) & & Inappropriate Communication \\
\hline \multirow{7}{*}{$\begin{array}{l}\text { J. L. Seminara and } \\
\text { R. W. Pack (1982) }\end{array}$} & \multicolumn{2}{|c|}{ Inability to communicate with personnel located in high noise areas } \\
\hline & \multicolumn{2}{|c|}{ Requirement for additional forms of communication devices } \\
\hline & \multicolumn{2}{|c|}{ Insufficient capacity or coverage with existing communications system } \\
\hline & \multicolumn{2}{|c|}{ Unreliable or faulty communication equipment } \\
\hline & \multicolumn{2}{|c|}{ Arrangement of communications equipment in the control room } \\
\hline & \multicolumn{2}{|c|}{ Communication system control problems } \\
\hline & \multicolumn{2}{|c|}{ Miscellaneous } \\
\hline \multirow{12}{*}{$\begin{array}{c}\text { J. Berman and } \\
\text { H. Gibson (1994) }\end{array}$} & \multicolumn{2}{|c|}{ Misunderstanding (sender/receiver failure not identified) } \\
\hline & \multicolumn{2}{|c|}{ Inadequate communication (sender/receiver failure not identified) } \\
\hline & \multicolumn{2}{|c|}{ Not communicated (sender failure) } \\
\hline & \multicolumn{2}{|c|}{ Inadequate message processing by receiver } \\
\hline & \multicolumn{2}{|c|}{ Communication failure unknown } \\
\hline & \multicolumn{2}{|c|}{ Inadequate medium } \\
\hline & \multicolumn{2}{|c|}{ Inadequate sender message } \\
\hline & \multicolumn{2}{|c|}{ Radio Causes equipment interference } \\
\hline & \multicolumn{2}{|c|}{ Communicate to wrong person (sender failure) } \\
\hline & \multicolumn{2}{|c|}{ Communication distracts from/interrupts task } \\
\hline & \multicolumn{2}{|c|}{ Receiver fails to seek clarification of status } \\
\hline & \multicolumn{2}{|c|}{ Receiver fails to locate sent message } \\
\hline \multirow{12}{*}{ U. S. NRC (1997) } & \multirow{8}{*}{$\begin{array}{l}\text { Sending } \\
\text { Errors }\end{array}$} & Message content is wrong \\
\hline & & Message content is inconsistent with other information \\
\hline & & Message content is inappropriate for the receiver \\
\hline & & Message production is inadequate \\
\hline & & Message is not sent \\
\hline & & Message is sent to the wrong place or person \\
\hline & & Message is sent at the wrong time \\
\hline & & Failure to verify that the receiver understands the message \\
\hline & \multirow{4}{*}{$\begin{array}{l}\text { Receiving } \\
\text { Errors }\end{array}$} & Message is not sought \\
\hline & & Message is not found or is not used \\
\hline & & Message is misunderstood \\
\hline & & Receiver does not verify sender correct understanding of the message \\
\hline \multirow{4}{*}{$\begin{array}{l}\text { R. Fukuda and } \\
\text { O. Strater (2004) }\end{array}$} & \multicolumn{2}{|c|}{ Misunderstandings due to addressee's false association about system meant by speaker } \\
\hline & $\begin{array}{l}\text { Lack of co } \\
\text { addressee' }\end{array}$ & $\begin{array}{l}\text { munication due to speakers reluctance, mainly due to wrong perception (imagination) of the } \\
\text { heeds }\end{array}$ \\
\hline & Lack of co & munication mainly due to addressee's wrong identification of information \\
\hline & Break-dow & of communication mainly due to lack of co-ordination between speaker and addressee \\
\hline & Message is & ent at the wrong time \\
\hline & Message is & ot sent at all \\
\hline & Message is & ent with an uncommon acoustic feature \\
\hline S M Jee et al (2010) & Message is & ent to the wrong place or person \\
\hline & Message se & through inadequate route \\
\hline & Message $\mathrm{p}$ & duction is inadequate \\
\hline & Message ce & tent is inappropriate for the receiver \\
\hline & Message co & tent is inconsistent with other information \\
\hline
\end{tabular}


Table 3. Existing Taxonomies of Inappropriate Communications in the Aviation industry

\begin{tabular}{|c|c|c|}
\hline Authors (Year) & & Inappropriate Communication \\
\hline \multirow{9}{*}{$\begin{array}{l}\text { R. L. Grayson and } \\
\text { C. E. Billings (1981) }\end{array}$} & \multicolumn{2}{|c|}{ Misinterpretable - phonetic similarity } \\
\hline & \multicolumn{2}{|c|}{ Inaccurate - transposition } \\
\hline & \multicolumn{2}{|c|}{ Other inaccuracies in content } \\
\hline & \multicolumn{2}{|c|}{ Incomplete content } \\
\hline & \multicolumn{2}{|c|}{ Ambiguous phraseology } \\
\hline & \multicolumn{2}{|c|}{ Untimely transmission } \\
\hline & \multicolumn{2}{|c|}{ Garbled phraseology } \\
\hline & \multicolumn{2}{|c|}{ Absent - not sent } \\
\hline & \multicolumn{2}{|c|}{ Recipient not monitoring } \\
\hline \multirow{4}{*}{ R. Morrison (1989) } & \multicolumn{2}{|c|}{ Clearance Composition } \\
\hline & \multicolumn{2}{|l|}{ Phraseology } \\
\hline & \multicolumn{2}{|l|}{ Delivery } \\
\hline & \multicolumn{2}{|c|}{ Readback/Hearback } \\
\hline \multirow{9}{*}{$\begin{array}{l}\text { D. Morrow et al. } \\
\text { (1991) }\end{array}$} & \multirow{3}{*}{$\begin{array}{l}\text { Understandi } \\
\text { ng Problems }\end{array}$} & Addressee signals misunderstanding \\
\hline & & Speaker repeats to get evidence of understanding \\
\hline & & Controller corrects erroneous pilot readback \\
\hline & \multirow{6}{*}{$\begin{array}{l}\text { Information } \\
\text { Problems }\end{array}$} & Self-correction \\
\hline & & Addressee updates speaker message \\
\hline & & Incomplete message \\
\hline & & Speaker asks for other information \\
\hline & & Pilot has to ask for command \\
\hline & & Pilot challenges appropriateness of a command \\
\hline \multirow{4}{*}{ J. A. Volpe (1998) } & \multicolumn{2}{|c|}{ Absent of readback } \\
\hline & \multicolumn{2}{|c|}{ Readback error/ Hearback error } \\
\hline & \multicolumn{2}{|c|}{ Hearback error type 2} \\
\hline & \multicolumn{2}{|c|}{ Misunderstanding } \\
\hline \multirow{8}{*}{ L. L. Bailey (2001) } & \multicolumn{2}{|l|}{ Phraseology } \\
\hline & Transpositio & \\
\hline & Misundersta & ading \\
\hline & & Altitude \\
\hline & Readback & Clearance \\
\hline & & Identification \\
\hline & Acknowledg & ment \\
\hline & Other & \\
\hline & Slip & \\
\hline & No readback & \\
\hline & No response & \\
\hline & Contradict $\mathrm{p}$ & evious instruction \\
\hline & Query & \\
\hline Gibson (2008) & Context requ & ired \\
\hline & Use of own & anguage (not English) \\
\hline & Change of $\mathrm{p}$ & \\
\hline & Break & \\
\hline & Station calli & \\
\hline & Expedite & \\
\hline
\end{tabular}




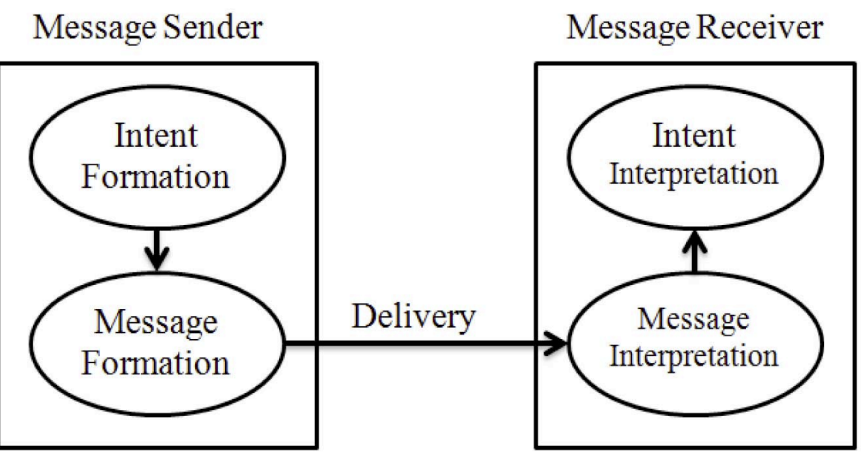

Fig. 1. Simplified One-way Communication Model

\subsection{Existing Taxonomies in Railway Field}

K. Oien and R. Rosness [20] developed a type of change analysis method for the evaluation of the effect on safety due to the introduction of condition monitoring equipment for maintenance of railway components. They classified inappropriate communications based on action error mode analysis (AEMA). P. Murphy [4] examined how problems with safety critical communications can lead to incidents or accidents within possessions on the rail infrastructure. P. Murphy categorized inappropriate communications based on pre-sets in the root cause analysis tool (RCAT) used in that study as a data collection tool. P. Shanahan et al. [21] tried to improve understanding of how much inappropriate communications contribute to causing incidents and under what circumstances. They classified inappropriate communications based on the technique for the retrospective and predictive analysis of cognitive errors (TRACEr). H. Gibson et al. [9] tried to provide further investigation of inappropriate communications during railway maintenance. Their taxonomy provides three dimensions for the classification of inappropriate communications that can be added to broader classification systems in order to optimize classification of inappropriate communications. The three classification elements are the criteria of inappropriate communications, the level of the grammar, and external error modes. Table 4 shows the taxonomy of inappropriate communications that has been developed in the railway industry.

\subsection{Existing Taxonomies in Medical Field}

J. Reason [22] investigated organizational factors affecting anesthesia mishaps in the medical industry. He classified inappropriate communications into slips and lapses. A. L. Halverson et al. [23] characterized inappropriate communications in the operating room and evaluated the effects of inappropriate communications to improve communications between members of the operating room team. They used the existing taxonomy of inappropriate communications that was developed by Lingard et al. [24] based on a rhetorical framework which is particularly useful for examining group discourse in complex social settings, as it considers the content of communications alongside three other critical factors: audience, purpose, and occasion. Table 5 shows taxonomy of inappropriate communications that has been developed in the medical industry.

\section{NEW TAXONOMY OF INAPPROPRIATE COMMUNICATIONS}

In order to develop a new taxonomy of inappropriate communications, we investigated the existing taxonomies in the four chosen industries from 1980 to 2011. However, the existing taxonomies seem to have the problem of uncertainty. To unravel the problem of uncertainty, we first re-categorized types of inappropriate communications based on the simplified one-way communication model suggested by Y. H. Chung [26]. The simplified one-way communication model is drawn in Figure 1.

As shown in Figure 1, there are three kinds of the sources for inappropriate communications: the message sender, the delivery, and the message receiver. In consideration of these sources, inappropriate communications can be classified into four types: (1) type A: message sender, (2) type B: delivery, (3) type C: message receiver, and (4) type D: external factors. Inappropriate communications corresponding to the factors related to the message sender such as intent formation and message formation are classified as type A. For example, 'phraseology' and 'incorrect information' are categorized as type A and 'no communication' and 'no readback' are categorized as type B. Moreover, inappropriate communications corresponding to factors related to the message receiver such as intent interpretation and message interpretation are classified as type C. For example, 'misunderstanding' is categorized as type $\mathrm{C}$.

Table 6 summarizes the result of re-categorization of inappropriate communications based on the simplified oneway communication model. As shown in Table 6, it seems that most researchers have focused on type A problems, which involve the message sender, and type B problems, which involve delivery, except J. L. Seminara et al. who 
Table 4. Existing Taxonomies of Inappropriate Communications in the Railway Industry

\begin{tabular}{|c|c|c|}
\hline Authors (Year) & & Inappropriate Communication \\
\hline \multirow{11}{*}{$\begin{array}{l}\text { K. Oien and R. Rosness } \\
\text { (1998) }\end{array}$} & \multicolumn{2}{|l|}{ Premature } \\
\hline & \multicolumn{2}{|l|}{ Omission } \\
\hline & \multicolumn{2}{|l|}{ Too late } \\
\hline & \multicolumn{2}{|l|}{ Too little } \\
\hline & \multicolumn{2}{|l|}{ Too much } \\
\hline & \multicolumn{2}{|l|}{ Too long } \\
\hline & \multicolumn{2}{|l|}{ Too slow } \\
\hline & \multicolumn{2}{|l|}{ Too fast } \\
\hline & \multicolumn{2}{|c|}{ Wrong direction } \\
\hline & \multicolumn{2}{|c|}{ Wrong object } \\
\hline & \multicolumn{2}{|c|}{ Wrong action } \\
\hline \multirow{10}{*}{ P. Murphy (2001) } & \multicolumn{2}{|c|}{ Did not attempt Communication; violation } \\
\hline & \multicolumn{2}{|c|}{ Passing on incomplete information } \\
\hline & \multicolumn{2}{|c|}{ Passed on wrong information } \\
\hline & \multicolumn{2}{|c|}{ Communication Breakdown; human issues } \\
\hline & \multicolumn{2}{|c|}{ Link not set up; Human Issues } \\
\hline & \multicolumn{2}{|c|}{ Not repeating Messages back } \\
\hline & \multicolumn{2}{|c|}{ Not checking Details given } \\
\hline & \multicolumn{2}{|c|}{ Did not attempt Communication; Technical } \\
\hline & \multicolumn{2}{|c|}{ Clear Understanding not reached } \\
\hline & Did not Com & municate; forget \\
\hline & No Commun & ication \\
\hline & Wrong Inforn & mation \\
\hline & Wrong Timir & \\
\hline & Incomplete & \\
\hline & Unclear & \\
\hline P. Shananan et al. & Badly Expres & ssed \\
\hline & Misheard & \\
\hline & Did not Liste & \\
\hline & Failure to $\mathrm{Re}$ & ach \\
\hline & Common Un & derstanding \\
\hline & Reached Con & nmon but Incorrect Understanding \\
\hline & Communica & Communication failure \\
\hline & tion Error & Deviations from the grammar \\
\hline & Criteria & Task communication errors \\
\hline & & Phonology \\
\hline & Level of & Semantics \\
\hline & Grammar & Syntax \\
\hline & & Pragmatics \\
\hline & & Omit \\
\hline H Gibson et al (2006) & & Wrong action right object \\
\hline H. Gibson et al. (2006) & & Right action wrong object \\
\hline & & Wrong action Wrong object \\
\hline & & Wrong direction \\
\hline & $\begin{array}{l}\text { External } \\
\text { Error Mode }\end{array}$ & Repeated \\
\hline & & Mis-ordered \\
\hline & & Too much / too little \\
\hline & & Too long/ Too short \\
\hline & & Too early/late \\
\hline & & Extraneous act \\
\hline
\end{tabular}


Table 5. Existing Taxonomies of Inappropriate Communications in the Medical Industry

\begin{tabular}{|c|c|c|}
\hline Authors (Year) & & Inappropriate Communication \\
\hline \multirow{2}{*}{ J. Reason (1995) } & \multicolumn{2}{|l|}{ Slips } \\
\hline & \multicolumn{2}{|l|}{ Lapses } \\
\hline \multirow{6}{*}{ T. Matsuo (2005) [25] } & \multirow{3}{*}{$\begin{array}{c}\text { Incorrect } \\
\text { Communication }\end{array}$} & Incorrect information is communicated \\
\hline & & Ambiguous information is communicated \\
\hline & & Communicated information is incorrectly interpreted \\
\hline & \multirow{3}{*}{$\begin{array}{l}\text { Communication } \\
\text { Inability }\end{array}$} & Communication is not performed \\
\hline & & Confirmation is not performed \\
\hline & & It is hard to communication for a certain reason \\
\hline \multirow{6}{*}{$\begin{array}{l}\text { A. L. Harverson et al. } \\
\qquad(2010)\end{array}$} & \multicolumn{2}{|l|}{ Content } \\
\hline & \multicolumn{2}{|l|}{ Occasion } \\
\hline & \multicolumn{2}{|l|}{ Purpose } \\
\hline & \multicolumn{2}{|l|}{ Audience } \\
\hline & \multicolumn{2}{|l|}{ Omission } \\
\hline & \multicolumn{2}{|l|}{ Inappropriate } \\
\hline
\end{tabular}

Table 6. The Re-categorization of the Inappropriate Communications Based on the Simplified One-way Communication Model

\begin{tabular}{|c|c|c|c|c|}
\hline Authors (Year) & Type A & Type B & Type C & Type D \\
\hline $\begin{array}{l}\text { J.L. Seminara } \\
\text { et al (1982) }\end{array}$ & & & & $\begin{array}{l}\text { Inability to Communicate with } \\
\text { personnel located in high noise } \\
\text { areas, Requirement for additional } \\
\text { forms of communication devices, } \\
\text { Insufficient capacity or coverage } \\
\text { with existing communication } \\
\text { system, Unreliable or faulty } \\
\text { communication equipment, } \\
\text { arrangement of communications } \\
\text { equipment in the control room, } \\
\text { Communication system control } \\
\text { problems, Miscellaneous }\end{array}$ \\
\hline $\begin{array}{l}\text { J. Berman et } \\
\text { al (1994) }\end{array}$ & $\begin{array}{l}\text { Inadequate sender } \\
\text { message }\end{array}$ & $\begin{array}{l}\text { Inadequate communication, Receiver } \\
\text { fails to seek clarification of status, } \\
\text { Communication distracts from/ } \\
\text { interrupts task, Not communicated, } \\
\text { Communicate to wrong person }\end{array}$ & $\begin{array}{l}\text { Misunderstanding, } \\
\text { Inadequate message } \\
\text { processing by receiver, } \\
\text { Receiver fails to locate } \\
\text { sent message }\end{array}$ & $\begin{array}{c}\text { Inadequate medium, Radio } \\
\text { causes equipment interference, } \\
\text { Communication failure unknown }\end{array}$ \\
\hline $\begin{array}{l}\text { U.S. NRC } \\
\text { (1997) }\end{array}$ & $\begin{array}{l}\text { Message content is } \\
\text { wrong, Message content } \\
\text { is inconsistent with } \\
\text { other information, } \\
\text { Message content is } \\
\text { inappropriate for the } \\
\text { receiver }\end{array}$ & $\begin{array}{l}\text { Message production is inadequate, } \\
\text { Message is not sent, Message is sent to } \\
\text { the wrong place or person, Message is } \\
\text { sent at the wrong time, Failure to verify } \\
\text { that the receiver understands the } \\
\text { message, Message is not found or is not } \\
\text { used, Receiver does not verify sender } \\
\text { correct understanding of the message }\end{array}$ & $\begin{array}{l}\text { Message is sought, } \\
\text { Message is } \\
\text { misunderstood }\end{array}$ & \\
\hline $\begin{array}{l}\text { R. Fukuda } \\
\text { (2004) }\end{array}$ & & $\begin{array}{l}\text { Lack of communication, Breakdown } \\
\text { of communication }\end{array}$ & Misunderstanding & \\
\hline $\begin{array}{l}\text { S. M. Lee } \\
(2010)\end{array}$ & $\begin{array}{l}\text { Message content is } \\
\text { inappropriate for the } \\
\text { receiver, Message } \\
\text { content is inconsistent } \\
\text { with other information }\end{array}$ & $\begin{array}{l}\text { Message is sent at the wrong time, } \\
\text { Message is not sent at all, Message is } \\
\text { sent to the wrong place or person, } \\
\text { Message sent through inadequate route, } \\
\text { Message production is inadequate }\end{array}$ & & $\begin{array}{l}\text { Message is sent with an } \\
\text { uncommon acoustic feature }\end{array}$ \\
\hline $\begin{array}{l}\text { R. L. } \\
\text { Grayson et al } \\
(1981)\end{array}$ & $\begin{array}{l}\text { Misinterpretable-phonetic } \\
\text { similarity, Inaccurate- } \\
\text { transposition, Other } \\
\text { inaccuracies in content, } \\
\text { Incomplete content, } \\
\text { Ambiguous phraseology, } \\
\text { Garbled phraseology }\end{array}$ & $\begin{array}{l}\text { Untimely transmission, Absent-not } \\
\text { sent, Absent-equipment failure }\end{array}$ & $\begin{array}{l}\text { Recipient not } \\
\text { monitoring }\end{array}$ & \\
\hline
\end{tabular}


Table 6. The Re-categorization of the Inappropriate Communications Based on the Simplified One-way Communication Model

\begin{tabular}{|c|c|c|c|c|}
\hline Authors (Year) & Type A & Type B & Type C & Type D \\
\hline $\begin{array}{l}\text { R. Morrison } \\
\text { (1989) }\end{array}$ & $\begin{array}{l}\text { Clearance composition, } \\
\text { Phraseology }\end{array}$ & Readback/Hearback, Delivery & & \\
\hline $\begin{array}{l}\text { D. Morrow } \\
\text { (1991) }\end{array}$ & $\begin{array}{l}\text { Incomplete message, } \\
\text { Speaker asks for other } \\
\text { information, Pilot has to } \\
\text { ask for command, Pilot } \\
\text { challenges appropriate- } \\
\text { ness of a command }\end{array}$ & $\begin{array}{l}\text { Speaker repeats to get evidence of } \\
\text { misunderstanding, Controller corrects } \\
\text { erroneous pilot readback, Self- } \\
\text { correction, Addressee updates speaker } \\
\text { message }\end{array}$ & $\begin{array}{l}\text { Addressee signal } \\
\text { misunderstanding }\end{array}$ & \\
\hline $\begin{array}{l}\text { J. A. Volpe } \\
\text { (1998) }\end{array}$ & & $\begin{array}{l}\text { Absent of readback, Readback error, } \\
\text { Hearback error, Hearback error type } 2\end{array}$ & & \\
\hline $\begin{array}{l}\text { L. L. Bailey } \\
\text { (2001) }\end{array}$ & $\begin{array}{l}\text { Phraseology, } \\
\text { Transposition }\end{array}$ & Readback, Acknowledgement & Misunderstanding & others \\
\hline $\begin{array}{l}\text { B. Kirwan } \\
\text { (2008) }\end{array}$ & $\begin{array}{l}\text { Slip, Contradict previous } \\
\text { instruction, Query, } \\
\text { Context required, Use of } \\
\text { own language, Change } \\
\text { of plan, Station calling, } \\
\text { Expedite }\end{array}$ & No readback, No response, Break & & \\
\hline $\begin{array}{l}\text { K. Oien } \\
(1998)\end{array}$ & $\begin{array}{l}\text { Too little, Too much, } \\
\text { Too long, Too slow, Too } \\
\text { fast, Wrong object }\end{array}$ & $\begin{array}{l}\text { Premature, Omission, Too late, } \\
\text { Wrong direction }\end{array}$ & Wrong action & \\
\hline $\begin{array}{l}\text { P. Murphy } \\
\text { (2001) }\end{array}$ & $\begin{array}{l}\text { Passing on incomplete } \\
\text { information, Passed on } \\
\text { wrong information }\end{array}$ & $\begin{array}{l}\text { Did not attempt communication- } \\
\text { violation, Communication } \\
\text { breakdown-human issues, No } \\
\text { repeating message back }\end{array}$ & $\begin{array}{l}\text { Not checking details } \\
\text { given }\end{array}$ & Link not set up-human issue \\
\hline $\begin{array}{l}\text { P. Shanahan } \\
\text { (2005) }\end{array}$ & $\begin{array}{l}\text { Wrong information, } \\
\text { Incomplete, Unclear, } \\
\text { Badly expressed }\end{array}$ & $\begin{array}{l}\text { No communication, Wrong timing, } \\
\text { Misheard, Failure to reach }\end{array}$ & $\begin{array}{l}\text { Did not listen, } \\
\text { Reached common but } \\
\text { incorrect } \\
\text { understanding }\end{array}$ & \\
\hline $\begin{array}{l}\text { W. H. Gibson } \\
\text { (2006) }\end{array}$ & $\begin{array}{l}\text { Phonology, Syntax, } \\
\text { Semantics, Pragmatics }\end{array}$ & Communication failure & & Task communication error \\
\hline $\begin{array}{l}\text { J. Reason } \\
\text { (1995) }\end{array}$ & Slip & Lapses & & \\
\hline $\begin{array}{l}\text { T. Matsuo } \\
\text { (2005) }\end{array}$ & $\begin{array}{l}\text { Incorrect information is } \\
\text { communicated, } \\
\text { Ambiguous information } \\
\text { is communication }\end{array}$ & Communication is not performed & $\begin{array}{l}\text { Communicated } \\
\text { information is } \\
\text { incorrectly interpreted }\end{array}$ & $\begin{array}{l}\text { It is hard to communicate for a } \\
\text { certain reason }\end{array}$ \\
\hline $\begin{array}{l}\text { A. L. } \\
\text { Halverson } \\
(2010)\end{array}$ & Content, Purpose & $\begin{array}{l}\text { Occasion, Omission, Inappropriate } \\
\text { (offensive remarks) }\end{array}$ & Audience & \\
\hline
\end{tabular}

were mostly focused on type D problems, which relate to external factors.

It seems that most inappropriate communications find their sources in the message sender and in delivery, and if the intent of formation, message formation, and delivery are appropriate, the possibility of inappropriate communications will be reduced.

In order to develop a taxonomy of inappropriate communications, we have reclassified all kinds of inappropriate communications based on the simplified one-way commu- nication model without any overlapping.

A new taxonomy of inappropriate communications developed in this study is shown in Table 7. Based on the simplified one-way communication model, there are four types of sources for inappropriate communications. Since 'inappropriate message contents' and 'phraseology and transposition' are related to the message sender, they are included in type A. In order to calculate the number of 'inappropriate message contents', the message contents from the verbal protocol data are compared with the related 
Table 7. A New Taxonomy of Inappropriate Communications

\begin{tabular}{c|c|c}
\hline & $\begin{array}{c}\text { Types of inappropriate } \\
\text { communications }\end{array}$ & Description \\
\hline \multirow{2}{*}{ Type A } & Inappropriate message contents & The information contained in the message is inappropriate to the receiver. \\
\cline { 2 - 3 } & Phraseology and transposition & The utterance has inappropriate phraseology and transition. \\
\cline { 2 - 4 } & Communication to wrong person & Message is transmitted to wrong person. \\
\cline { 2 - 4 } Type B & No communication & Message is not transmitted to the receiver \\
\cline { 2 - 3 } & Inappropriate readback & The utterance of the sender is not repeated (readback) by the receiver. \\
\cline { 2 - 3 } & Inappropriate hearback & An incorrect repeat of the sender's transmission by the receiver. \\
\cline { 2 - 3 } & Inappropriate hearback type 2 & The failures, on the sender's part, to notice his/her own error in the receiver's correct readback. \\
\cline { 2 - 3 } Type C & Repetition of message & The contents of message are repetitive since receiver is misunderstood or does not listen. \\
\hline \multirow{2}{*}{ Type D } & Inadequate Medium & Sources of poor production may include communication equipment problems. \\
\cline { 2 - 3 } & Miscellaneousness & Miscellaneousness \\
\hline
\end{tabular}

procedure. If the message contents are different from the related procedure, they are included as inappropriate communications.

There are various kinds of inappropriate communications included in type B which are related to the source of 'delivery'. In order to calculate the amount of content 'no communication', the message contents are again compared with the related procedure because of the assumption that 3-way communications for each step of procedure should be performed. For example, if any steps in the procedure are not uttered, they are considered as not having been communicated between operators. In addition, 'no communication' is clearly distinguished from 'no response' and 'no readback'. When communication is not performed since the sender does not transmit a message to the receiver, it is the type of 'no communication'. 'No response' is communication that does not receive a response by the receiver. The sender gives information to the receiver, but the receiver does not respond to the information. In the case of 'no readback', it is that communication is not repeated (readback) by the receiver. The sender gives clear commands to the receiver, but the receiver just responses the message without any readback.

In type $\mathrm{C}$, there is only one kind of inappropriate communication, which is 'repetition of message'. This is developed based on the assumption that if the message receiver does not listen or misunderstands the utterance of the message sender, the receiver should query the message sender or the message sender should utter the content once again to facilitate the task. In this regard, if the message sender or the message receiver utters the same contents again, it is a kind of 'repetition of message'. In type D, there are two kinds of inappropriate communications: which are 'inappropriate medium' and 'miscellaneousness'.

In the next section, it will be explained how to identify inappropriate communications from the verbal protocol data, based on the newly developed taxonomy of inappropriate communications.

\section{CASE STUDY TO IDENTIFY INAPPROPRIATE COMMUNICATIONS USING THE NEWLY DEVELOPED TAXONOMY}

As shown in previous sections, the taxonomy of inappropriate communications proposed above was developed to enhance the practicability of previous schemes, and the ratio of inappropriate communications according to this taxonomy was therefore compared with performance scores to provide insights to secure the safety of nuclear power plants. The ratio of inappropriate communications is calculated by counting the inappropriate communications from the verbal protocol data. In addition, the performance scores are calculated based on the task analysis resulting from the ideal path of the simulation scenarios.

Since inappropriate communications can be a source of human error in a stressful environment such as the emergency conditions of NPPs [7], verbal protocol data were collected under the off-normal condition of a fullscope simulator of the reference NPPs. This full-scope simulator is a replica of the MCR of a conventional 1,000MWe Westinghouse three-loop pressurized water reactor (PWR).

There are five kinds of operators, including supervisory reactor operators (SROs), reactor operators (ROs), turbine operators (TOs), electrical operators (EOs), and shift technical advisors (STAs) in the MCR of NPPs [27]. SROs are responsible for all kinds of tasks under emergency conditions. SROs request various kinds of information and command the board operators (TOs, EOs, and ROs) to 


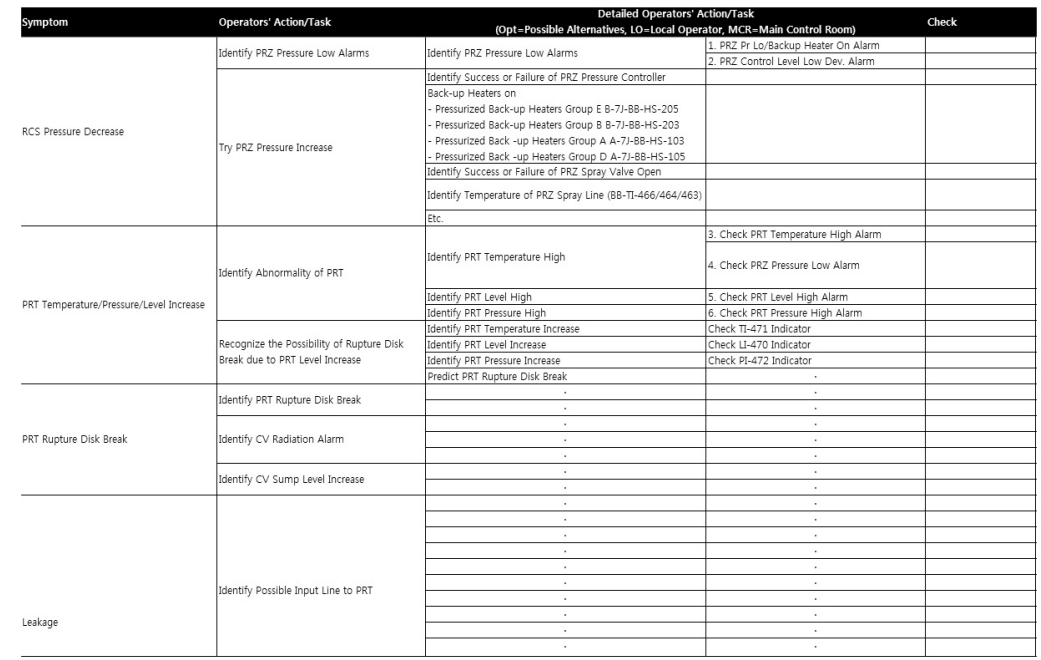

Fig. 2. The Optimal Solution Sheet for ISLOCA Scenario

accomplish required tasks. ROs and TOs are responsible for the primary loop and the secondary loop in NPPs, respectively, and EOs are responsible for the electrical power of NPPs. They should provide required information and execute commands to support SROs. STAs are responsible for checking the status of critical safety functions in NPPs.

All communications between operators are recorded in an audio-visual format and transcribed to the verbal protocol data. We collected the verbal protocol data of eight different operating teams during the interfacing system loss of coolant accident (ISLOCA) scenario, which is the one of the emergency conditions. The verbal protocol data included five kinds of information: the time when each operator started to communicates, the time when each communication was finished, the identity of each operator (SRO, RO, EO, TO, and STA) who initiated communications, the associated category of inappropriate communications, and communication contents which were uttered by each operator.

The ISLOCA scenario is referred from nuclear regulation/control room-6208 (NUREG/CR-6208) [28]. The ISLOCA scenario was designed to be difficult from the point of view of situation assessment. The objective was to create a situation where the crews had to identify and isolate a leak in the Residual Heat Removal (RHR) system without explicit procedural guidance. This situation assessment was cognitively demanding because initial symptoms were typical of a Loss of Coolant Accident (LOCA) inside containment. In this scenario, it is expected that the operators' performance score can be explicitly affected by the occurrence of inappropriate communications since handling a complex scenario demands a higher level of cognitive activities from operators in the MCR even when Emergency Operating Procedures (EOPs) are used.

Performance score is calculated based on the task performance measure. Basically, the task performance measure provides a means of measuring the number of tasks completed by operators or a team. To perform the task performance measure, task analysis that yields the optimal solution to resolve the accident is primarily performed and each required task is weighted according to importance. Then, performance score of each team is calculated based on the operator's behavior such as communications between operators, simulation log, and control action [29].

Task analysis is the term applied to any process that identifies and examines tasks performed by humans as they interact with systems [30]. In order to perform task analysis, we identify tasks, collect task data, analyze the data, and product the optimal solution sheet based on the experts and EOPs. The optimal solution sheet is shown in Figure 2 and if human operators implement the required tasks, we checked the optimal solution sheet. Then, the total performance score for each team is calculated using the optimal solution sheet.

\section{RESULT}

As stated above, inappropriate communications can be identified from the verbal protocol data using the new taxonomy of inappropriate communications. In addition, comparisons between the ratios of inappropriate communications and the performance scores for eight different operating teams were performed.

The numbers of inappropriate communications are shown in Table 8, and total communications for each operating team varied from 199 to 500 . However, the ratio of 'no communication' is separated from the total ratio of inappropriate communications. This is because the calculations of 'no communication' are performed in the related procedures instead of the verbal protocol data with the assumption that 3-way communications for each step of 
Table 8. Results of the Number of Inappropriate Communications for Each Operating Team

\begin{tabular}{|c|c|c|c|c|c|c|c|c|c|}
\hline & $\begin{array}{l}\text { Types of inappropriate } \\
\text { communications }\end{array}$ & Team 1 & Team 2 & Team 3 & Team 4 & Team 5 & Team 6 & Team 7 & Team 8 \\
\hline \multirow{2}{*}{ Type A } & Inappropriate message contents & 2 & 5 & 3 & 1 & 6 & 15 & 19 & 24 \\
\hline & Phraseology and transposition & 3 & 3 & 4 & 4 & 5 & 8 & 8 & 5 \\
\hline \multirow{7}{*}{ Type B } & Communication to wrong person & 0 & 0 & 0 & 0 & 0 & 0 & 0 & 0 \\
\hline & No communication & 35 & 41 & 36 & 48 & 39 & 46 & 48 & 52 \\
\hline & No readback & 10 & 12 & 14 & 8 & 12 & 5 & 20 & 9 \\
\hline & Inappropriate readback & 0 & 0 & 2 & 0 & 0 & 0 & 0 & 0 \\
\hline & Inappropriate hearback & 0 & 0 & 0 & 0 & 0 & 0 & 0 & 0 \\
\hline & Hearback error type 2 & 0 & 0 & 0 & 0 & 0 & 0 & 0 & 0 \\
\hline & No response & 37 & 38 & 56 & 28 & 50 & 67 & 67 & 62 \\
\hline Type C & Repetition of message & 9 & 12 & 12 & 13 & 30 & 20 & 15 & 26 \\
\hline \multirow{2}{*}{ Type D } & Inappropriate medium & 0 & 0 & 0 & 0 & 0 & 0 & 0 & 0 \\
\hline & Miscellaneousness & 0 & 0 & 0 & 1 & 0 & 0 & 0 & 0 \\
\hline \multicolumn{2}{|c|}{ Total number of inappropriate communications } & 61 & 70 & 91 & 55 & 103 & 115 & 129 & 126 \\
\hline \multicolumn{2}{|c|}{ Total amount of communications } & 278 & 293 & 410 & 199 & 469 & 431 & 500 & 349 \\
\hline \multicolumn{2}{|c|}{ Total amount of items in the procedures } & 90 & 90 & 90 & 90 & 90 & 90 & 90 & 90 \\
\hline
\end{tabular}

Table 9. Results of the Ratios of Inappropriate Communications and 'no Communication' for Each Operating Team

\begin{tabular}{c|c|c}
\hline & The ratio of inappropriate communications & The ratio of 'no communication' \\
\hline Team 1 & 0.2194 & 0.3889 \\
\hline Team 2 & 0.2389 & 0.4556 \\
\hline Team 3 & 0.2220 & 0.4000 \\
\hline Team 4 & 0.2764 & 0.5333 \\
\hline Team 5 & 0.2196 & 0.4333 \\
\hline Team 6 & 0.2668 & 0.5111 \\
\hline Team 7 & 0.2580 & 0.5333 \\
\hline Team 8 & 0.3610 & 0.5778 \\
\hline
\end{tabular}

procedure should be performed. The ratios of inappropriate communications are also different between each operating team. In some categories such as 'communication to wrong person', 'inappropriate hearback', 'hearback error type 2', and 'miscellaneousness', the ratio was not shown from the verbal protocol data. In addition, as shown in Table 8 , the majority of inappropriate communications are included in the type B category, where delivery is the source of inappropriate communications.

As shown in Table 9, Team 1 has the lowest ratio of total inappropriate communications and the lowest ratio of 'no communication' among all 8 operating teams, and Team 8 has the highest value ratio of inappropriate communications and highest ratio of 'no communication' content among all 8 teams.

As stated above, the performance scores in Table 10 are calculated based on the task analysis and are distributed from the 28 to 57 . Team 1 has the highest value performance
Table 10. Result of Calculations for the Performance Score Based on the Task Analysis for Each Operating Team

\begin{tabular}{c|c}
\hline & The performance scores based on the task analysis \\
\hline Team 1 & 57 \\
\hline Team 2 & 50 \\
\hline Team 3 & 42 \\
\hline Team 4 & 48 \\
\hline Team 5 & 48 \\
\hline Team 6 & 47 \\
\hline Team 7 & 43 \\
\hline Team 8 & 28 \\
\hline
\end{tabular}

score among the eight operating teams, and Team 8 has the lowest value performance score among the eight operating teams. 


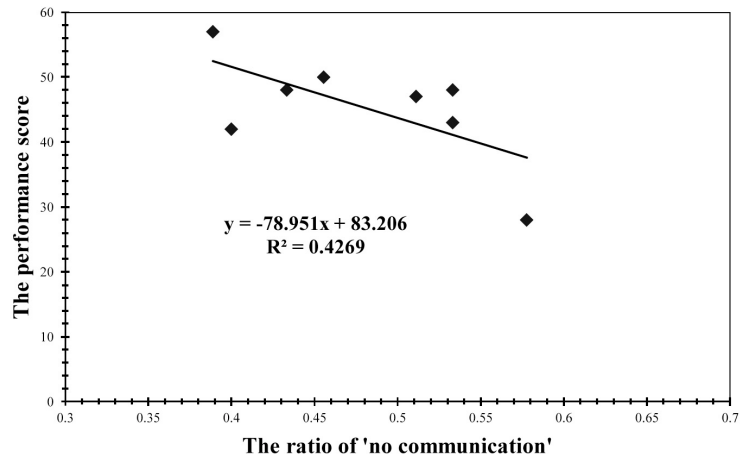

Fig. 3. The Comparison between the Performance Score and the Ratio of 'No Communication'

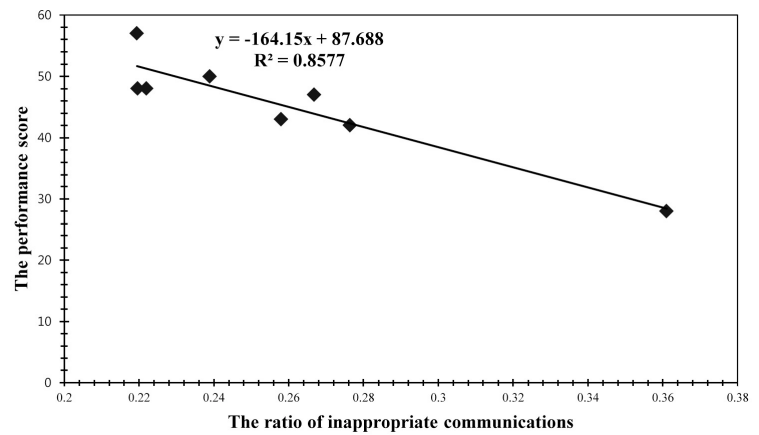

Fig. 4. The Comparison between the Performance Score and the Ratio of Inappropriate Communications

A comparison between the ratios of inappropriate communications and the performance scores is shown in Figure 4, and a comparison between the ratios of 'no communication' and the performance scores is shown in Figure 3. The values of $\mathrm{R}$ square are 0.4269 and 0.8577 , respectively. There is explicit relationship between the ratio of inappropriate communications and the performance scores.

\section{DISCUSSION AND CONCLUSION}

It is necessary to prevent the occurrence of inappropriate communications that can cause a variety of accidents in large process systems such as NPPs. In this regard, many researchers have made substantial efforts to develop taxonomies of inappropriate communications to investigate the causes and consequences of inappropriate communications. Unfortunately, identification of inappropriate communications from verbal protocols seems to be problematic, since most existing taxonomies have been developed for use in report analysis.

As mentioned before, we developed a new taxonomy of inappropriate communications based on a literature survey of four selected industries from 1980 to 2010 and the simplified one-way communication model. In the literature, there are three types of sources that can cause inappropriate communications (i.e., message sender, delivery, and message receiver) and four types of inappropriate communications can be considered from the sources (i.e., message sender, delivery, message receiver, and external factors). The categories of inappropriate communications collected from the literature survey were classified using the simplified one-way communication model. Also, the same results are derived using "success logic tree" that consists of trunks and leaves [31]. Accordingly, the taxonomy of inappropriate communications is seems to be clear.

Consequently, a new taxonomy of inappropriate communications is developed in this study, and we conducted a case study in order to test the applicability of the taxonomy. Using this taxonomy, we can practically identify inappropriate communications from verbal protocol data. In addition, the ratio of inappropriate communications was compared with the performance scores. Comparison results indicate that teams with lower performance scores are apt to commit inappropriate communications, which can be a source of human error under emergency conditions in NPPs.

The four main types of inappropriate communications such as 'no communication', 'no readback', 'no response' and 'repetition of message' are apt to be observed more than other types of inappropriate communications. We found that 'no communication' is by a large margin the most common inappropriate communications. Also, many researchers $[4,21]$ have considered 'no communications' is the biggest problem of inappropriate communications since it means that the sender does not give the necessary information to the receiver. In addition, J. H. Kim [32] represented that a decision maker showed that the potential for leading to wrong conclusion regarding the plant state when he makes a situational assessment or makes a decision based on abnormal information by himself without communicating or consulting with other operators.

Unfortunately, it seems premature to generalize the developed taxonomy of inappropriate communications because of the limited amount of verbal protocol data in the case study. Accordingly, we were unable to observe some types of inappropriate communications such as 'communication to wrong person', 'inappropriate readback', 'inappropriate hearback', and 'inappropriate medium'. Even though 'inappropriate readback' and 'inappropriate hearback' were not observed in the case study, these two types of inappropriate communications should be considered since they can have serious consequences; they can start a chain of events that can jeopardize safety and they contribute to operational errors [17]. For this reason, it is necessary to perform further studies to apply the developed taxonomy to different situations of NPPs.

Notwithstanding this limitation of the developed taxonomy, we consider that it can still provide some insights to reduce the occurrence of inappropriate communications within operating teams and enhance the exchange of adequate information to secure the safety of large process systems such as NPPs. 


\section{REFERENCES}

[1] J. Berman and H. Gibson, "Communication Failure in the Operation of Nuclear Power Plants", vol. 8, pp. 57-66 (1994).

[2] National Transportation Safety Board, "National Transportation Safety Board-Aircraft Accident Report-Trans World Airlines Flight 800", NTSB/AAR-00-01 (1996).

[3] Y. Hirotsu et al., "Multivariate Analysis of Human Error Incidents Occurring at Nuclear Power Plants: Several Occurrence Patterns of Observed Human Errors", Cognition, Technology \& Work, vol. 3, pp.82-91 (2001).

[4] P. Murphy, The Role of Communications In accidents and Incidents during Rail Possessions, Volume 5, p. 447-454, Engineering Psychology and Cognitive Ergonomics, Aerospace and Transportation System. Aldershot, UK: Ashgate (2001).

[5] R.L. Grayson and C.E. Billings, Information Transfer between Air Traffic Control and Aircraft: Communication Problems in Flight Operations, NASA Technical Paper 1875 (1981).

[6] R. Morrison and R. H. Wright, ATC Control and Communication Problems: An Overview of recent ASRS data. vol. 2, In (Ed: R. S. Jensen) Proceedings of the Fifth International Symposium of Aviation Psychology, Columbus, Ohio (1989).

[ 7 ] S. H. Kim et al., "Some Insights about the Characteristics of Communications Observed from the Off-normal Conditions in Nuclear Power Plants", Human Factors and Ergonomics in Manufacturing and Service Industries, vol. 21, 361-378 (2011)

[ 8 ] J. K. Park, "The Use of a Social Network Analysis Technique to Investigate the Characteristics of Crew Communications in Nuclear Power Plants-A Feasibility Study", Reliability Engineering and System Safety, vol. 96, pp. 1275-1291 (2011).

[9] H. Gibson et al., "A Taxonomy of Human Communication Errors and Application to Railway Track Maintenance", Cogn Tech Work, vol. 8, pp. 57-66 (2006).

[10] D.G. Morrow, A. Lee and M. Rodvold, Analysis of Routine Pilot-Controller Communication, In Managing the Modern Cockpit: Third Human Error Avoidance Technique Conference Proceedings, Warrendale PA: Society of Automotive Engineers, Inc. (1990).

[11] A. R. Kim et al., "Understanding Team Communication Characteristics Using Social Network Analysis", Transaction on American Nuclear Society, vol. 105, pp. 319-320 (2011).

[12] J. L. Seminara and R. W. Pack, "Communication Needs of the Nuclear Power Plant Operator", IEEE Transactions on Power Apparatus and System, vol. PAS-101, pp. 792-796 (1982).

[13] U.S. Nuclear Regulatory Commission, "Evaluation Criteria for Communications-Related Corrective Action Plans", NUREG-1545 (1997).

[14] R. Fukuda and O. Strater, Communication in Nuclear Power Plants (NPP), p. 55-74, Group Interaction in High Risk Environment (2004).

[15] S. M. Lee, J. S. Ha, P. H. Seong, “CREAM-based Communication Error Analysis Method (CEAM) for Nuclear Power Plants Operators' Communication", Journal of Loss Prevention in the Process Industries, vol. 24, pp. 90-97 (2011).

[16] D. Morrow, M. Rodvold and A. Lee, "Nonroutine Transac- tions in Controller-Pilot Communication", Discourse Processes, vol. 17, pp. 235-258 (1994).

[17] J. A. Volpe, "Pilot-Controller Communication Errors: An Analysis of Aviation Safety Reporting System (ASRS) Reports" AAR-100, U.S. Department of Transportation (1998).

[18] L. L. Bailey, B. F. Willems, and L. M. Peterson, "The Effects of Workload and Decision Support Automation on Enroute R-Side and D-Side Communication Exchanges", Technical reports DOT/FAA/AM-01/20, U.S. Department of Transportation (2001).

[19] B. Kirwan, W. H. Gibson, and B. Hickling, "Human Error Date Collection as a Precursor to the Development of a Human Reliability Assessment Capability in Air Traffic Management", Reliability Engineering and System Safety, vol. 93, pp.217-233 (2008).

[20] K. Oien and R. Rosness, "Methods for safety analysis in railway systems", Sintef report, STF38 A98426, SINTEF Industrial Management (1998).

[21] P. Shanahan, D. Gregory, M. Shannon and H. Gibson, "The Role of Communication Errors in Railway Incident Causation", Paper Presented at the Second European Conference on Rail Human Factors, London, England, Nov. 21-23 (2005).

[22] J. Reason, "Safety in the Operating Theatre - Part 2: Human Error and Organisational Failure", Current anesthesia and critical care, vol. 6, pp. 121-126 (1998).

[23] A.L. Halverson et al., "Communication Failure in the Operating Room”, Surgery, vol. 149, pp. 305-310 (2010).

[24] Lingard L, Regehr G, Orser B et al., "Evaluation of a Preoperative Checklist and Team Briefing among Surgeons, Nurses, and Anesthesiologists to Reduce Failures in Communication", Arch Surg, vol. 143, pp. 12-17 (2008).

[25] T. Matsuo, Lecture Note (2005).

[26] Y. H. Chung, "Research Trend of Communication Analysis and Human Error", Journal of Ergonomics of Society Korea, vol. 30, pp. 65-74 (2011).

[27] S. K. Kim et al., "Effectiveness of Crew Resource Management Training Program for Operators in the APR-1400 Main Control Room Simulator", IE Interface, vol. 22, pp. 105115 (2009).

[28] E. M. Roth et al., “An Empirical Investigation of Operator Performance in Cognitive Demanding Simulated Emergencies", NUREG/CR-6208, U.S. Nuclear Regulatory Commission (1994).

[29] I. S. Jang, J. K. Park, P. H. Seong., “A Study on Relationships between Functional Performance and Task Performance Measure through Experiments in NPP MCR", Paper Presented at the ICI2011 Conference, Daejeon, Korea, August 24-25, (2011).

[30] B. Kirwan, L. K. Ainsworth, A Guide to Task Analysis, Volume 8, Taylor \& Francis (2001).

[31] Y. S. Jung, Y. C. Shin, and I. S. Park, "An Incremental Objective Achievement Model in Computerized Procedure Execution", Reliability Engineering and System Safety, vol. 70, pp. 185-195 (2000).

[32] J. H. Kim, J. H. Kim, J. K. Park, S. C. Jang, and Y. C. Shin, "Some insights on Diagnostic Performance of the Operating Crew in a Computer-Based Advanced Control Room", Hu Industries, vol. 21, pp. 379-396 (2011). 